\title{
9 Safeguarding Water Resources by Making the Land Greener: Knowledge Management through WOCAT
}

\author{
Hanspeter Liniger ${ }^{1 *}$ and William Critchley ${ }^{2 * *}$ \\ ${ }^{1}$ Centre for Development and Environment, University of Berne, \\ Institute of Geography, Hallerstrasse 10, 3012 Bern, Switzerland; \\ ${ }^{2}$ Natural Resource Management Unit, CIS/Centre for International Cooperation, \\ Vrije Universiteit Amsterdam, 1081 HV Amsterdam, the Netherlands; \\ e-mails:*hanspeter.liniger@cde.unibe.ch; **wrs.critchley@dienst.vu.nl
}

\section{Introduction}

This chapter looks at the World Overview of Conservation Approaches and Technologies (WOCAT), which has a number of similarities with the 'bright spots' exercise. WOCAT's purpose and methodologies are briefly explained, its position in relation to other case study initiatives explored and its successes and limitations discussed. One summarized example from the WOCAT database is presented. An analysis of conservation approaches and technologies - from the WOCAT book Where the Land is Greener (WOCAT, 2007) - is presented. Finally, the bright spots' 'drivers' are reflected in terms of WOCAT's experience, and knowledge gaps are identified that still need to be addressed by research.

\section{A wealth of untapped knowledge in sustainable land management}

There has been a strong focus on studying and documenting soil degradation in the past, but a comprehensive presentation of sustainable land management (SLM) practices, and soil and water conservation (SWC) in particular, has not yet been undertaken (Liniger and Schwilch, 2002). In fact, a wealth of SLM knowledge and information exists, but the challenge is to collect this and make it available for exchange of know-how between land users and SLM specialists - including technicians, agricultural advisors, planners, coordinators and decision makers (see Box 9.1 for definitions).

As part of their daily activities, land users and SLM specialists regularly evaluate experience and generate knowledge related to land management, improvement of water-use efficiency, soil fertility and productivity, and protection of land resources. Most of this valuable knowledge, however, is not well documented or easily accessible, and comparison of different types of experience is difficult. Much SLM knowledge therefore remains a local, individual resource, unavailable to others working in similar areas, seeking to accomplish similar tasks. This is surely one of the reasons why soil degradation persists, despite many years of effort throughout the world and high investments in SLM.

In this context, WOCAT was established in 1992 as a global network of SLM specialists (Liniger and Schwilch, 2002; Hurni et al., 
Box 9.1. Definitions used by WOCAT

1. Sustainable Land Management (SLM): the use of land resources, including soils, water, animals and plants, for the production of goods to meet changing human needs, while simultaneously ensuring the long-term productive potential of these resources and ensuring their environmental functions.

2. Soil and Water Conservation (SWC): activities at the local level that maintain or enhance the productive capacity of the land in areas affected by, or prone to, degradation.

3. SLM Technologies: agronomic, vegetative, structural and/or management measures that prevent and control land degradation and enhance productivity in the field.

4. SLM Approaches: ways and means of support that help introduce, implement, adapt and apply SWC technologies on the ground.

2005). It is organized as an international consortium, coordinated by a management group and supported by a secretariat located at the Centre for Development and Environment, in Bern, Switzerland.

\section{A framework for the documentation, monitoring, evaluation and dissemination of SWC}

WOCAT's vision is that existing knowledge of sustainable land management is shared and used globally to improve livelihoods and the environment. WOCAT's mission is to support decision making and innovation in sustainable land management by connecting stakeholders, enhancing capacity, and developing and applying standardized tools for the documentation, evaluation, monitoring and exchange of soil and water conservation knowledge. The target group comprises sustainable land management specialists, planners and decision makers at the field and planning levels.

WOCAT has developed an internationally recognized, standardized methodology involving a set of three questionnaires to document relevant aspects of SLM Technologies and Approaches, including area coverage. A computer-based database system facilitates data entry, retrieval and evaluation. These tools have been tested in many workshops worldwide, and they have been systematically optimized over a period of 10 years through application in a context of international, national and local expertise.

Tools, results and outputs are accessible via the Internet, on CD-ROM and as books and maps, and are available in English, French and Spanish (www.wocat.net). The questionnaires on technologies and approaches are used together to describe case studies from the field. These are always linked to a specific area where the technology is applied, and to locally knowledgeable SLM specialists, who provide the information. The questionnaire on SLM Technologies addresses the specifications of the technology (purpose, classification, design and costs) and the natural and human environment where it is used. It also includes an analysis of the benefits, advantages and disadvantages, economic impacts, acceptance and adoption of the technology. The questionnaire on SLM Approaches focuses on implementation, with questions on objectives, operational aspects, participation by land users, financing, external material support and subsidies. Analysis of the described approach involves monitoring and evaluation methods as well as an impact analysis. The collection of information involves personal contacts and knowledge sharing between land users and SLM specialists. The immediate benefits of filling in the questionnaires include the compilation of fragmented information - often consisting of the undocumented experiences of land users and specialists - and a sound evaluation of one's own SLM activities. There is also a mapping questionnaire that addresses the issue of where degradation problems and their treatments occur. Some strength and weaknesses of WOCAT - as generally acknowledged - are listed in Box 9.2.

Figure 9.1 conceptualizes the WOCAT process and tools. It illustrates how knowledge from the field is tapped with questionnaires and stored in a database, from where it is further used to produce outputs that assist in the implementation of SLM. The ultimate beneficiaries of WOCAT are the land users: they should receive improved support by SLM specialists and through networks at national and international levels. 
Box 9.2. WOCAT strengths and weaknesses

Strengths:

- Works at field, national and global levels.

- Considers both socio-economic and ecological aspects.

- Fills a national and global gap in documentation, monitoring, evaluation and exchange.

- Sets global standards: methods, tools, outputs.

- Brings practitioners, researchers and planners together.

- Provides tools and a platform.

Weaknesses (proposed solutions in brackets):

- Demanding in terms of data collection for practitioners (use for self-evaluation, monitoring, training).

- Low quality of some data (national and international review panels).

- Problems in using tools (enhance training).

- Use of database for decision support at field and planning level (ongoing development of a decision support tool).

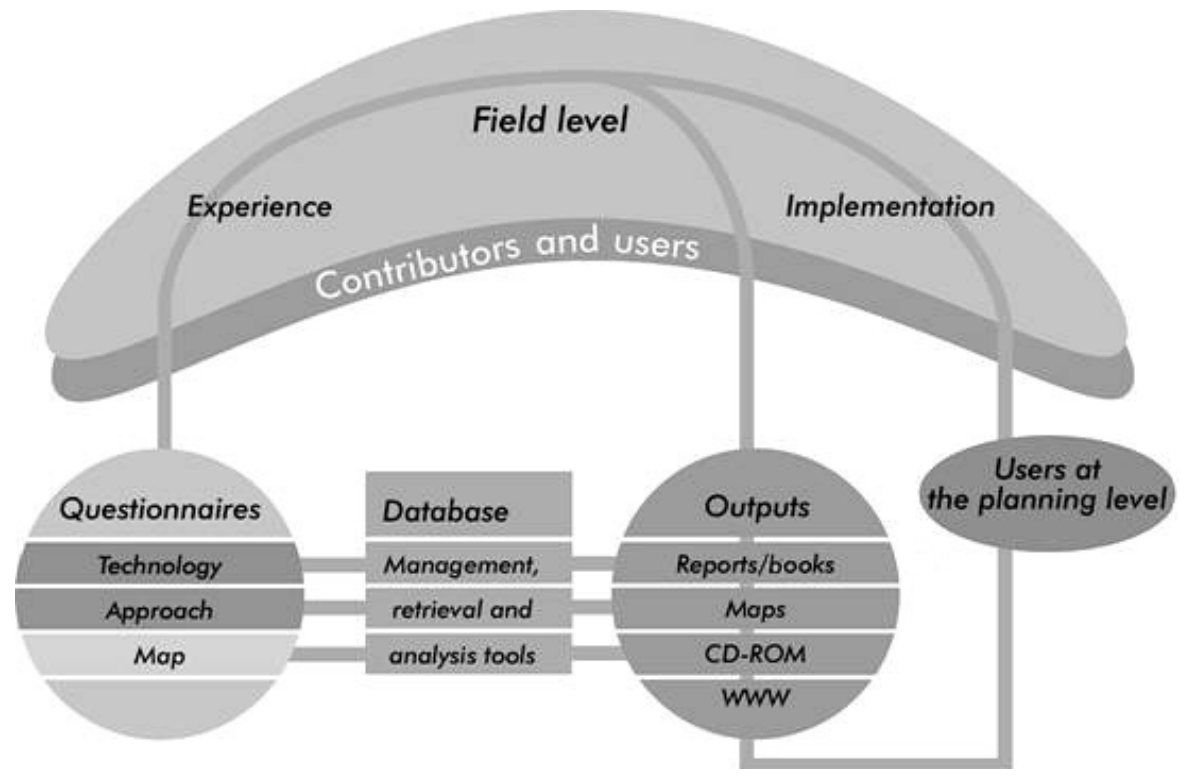

Fig. 9.1. WOCAT process and tools.

\section{A comparison of WOCAT and other 'success story' and 'best practice' initiatives}

The collection and compilation of 'success stories', 'best practices' or simply 'case studies' has long been used as a means of providing examples to illustrate points, prove theories or compile databases for later analysis. Through valuable tools, one common criticism of success story exercises is that they can be 'cherry picking': in other words the selection of cases is biased and proves points that are simply not generic. The WOCAT and the bright spots exercise belong to the category of widespread data collection: they both throw the net broadly and aim to analyse reasons for impact from a large database. WOCAT is characteristic - and unique in this respect - in that it is an ongoing exercise (having begun in 1992 and continuing until at least 2011) and is not a 'snapshot' review. Various other aspects make WOCAT somewhat different from other exercises. While its starting point is broadly 
'success' in sustainable land management, it also documents failures - or at least experience where there are mixed messages. Furthermore, it provides a standard international methodology, translated into several languages. WOCAT has recently become available at different levels of data-collection sophistication, from the original full WOCAT ('professional') questionnaires, to the trimmed down 'WOCAT-basic' questionnaire. What is more, WOCAT is simultaneously involved in training, capacity building and networking - in other words, much more than a simple case study collection initiative. Table 9.1 presents WOCAT and bright spots alongside some other related exercises.

\section{The WOCAT Book Where the Land is Greener}

So far, WOCAT tools have been used to document over 370 SLM Technologies and almost 240 SLM Approaches in over 45 countries in Africa, Asia, the Middle East, Europe and South America (see Box 9.3). Over 40 national and international WOCAT workshops have been held to collect data, develop and improve the methodology, train users, and enhance the network.

The collected, quality-controlled information has been made available on the Internet (www.wocat.net) and on CD-ROMs (WOCAT, 2004). Records of internet visits and requests for CD-ROMs show increasing demand and use of the electronic database and outputs. Part of this wealth of experience has been recently presented in a global overview book entitled Where the Land is Greener (WOCAT, 2007). It presents and analyses 42 technologies with 28 of their associated approaches from more than 20 countries, and analyses what is driving these positive trends. It will also act as a prototype for similar books to be compiled at the regional, national or other levels. The various case studies in the overview book show bright spots covering a wide range of improved land management activities - which include soil and water conservation and water harvesting, ranging from small-scale subsistence to large-scale commercial farming, covering a wide range of climates and SLM measures. The following groups of technologies are presented:

- Conservation agriculture (five case studies: Australia (×2), Kenya, Morocco, UK).

- Manuring/composting (three case studies: Burkina Faso, Nicaragua, Uganda).

- Vegetative strips (three case studies: the Philippines, South Africa, Switzerland).

- Agroforestry (eight case studies: China, Colombia, Costa Rica, Kenya, Kyrgyzstan, the Philippines, Tajikistan $(\times 2)$ ).

- Water harvesting (three case studies: India, Niger, Syria).

- Gully rehabilitation (three case studies: Bolivia, Nepal, Nicaragua).

- Terraces (nine case studies: China $(\times 2)$, Kenya, Nepal, Peru, the Philippines, South Africa, Syria, Thailand).

- Grazing land management (four case studies: Australia, Ethiopia $(\times 2)$, South Africa).

- Other technologies (four case studies: India $(\times 2)$, Niger, South Africa).

Each of the SLM Technologies and Approaches is presented in a standardized format of four pages each. Figure 9.2 shows selected aspects for one technology (the 'doh' water harvesting system from India), while Boxes 9.4 and 9.5 provide a summary of the doh sunken structure and the associated approach from Where the Land is Greener (WOCAT, 2007).

\section{How Sustainable Land Management is Spread}

The following comprises a summary of the section of Where the Land is Greener that

Box 9.3. WOCAT database and outputs

WOCAT's database currently comprises data sets on 374 technologies and 239 approaches, of which a subset of 161 technologies and 90 approaches are quality assured. The WOCAT knowledge base is in the public domain. Results and outputs are accessible in digital form, either via the Internet (www.wocat.net) or on CD-ROM. Where the Land is Greener is the first book compiled by WOCAT at the global level (WOCAT, 2007). 


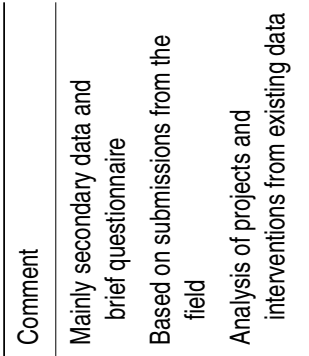
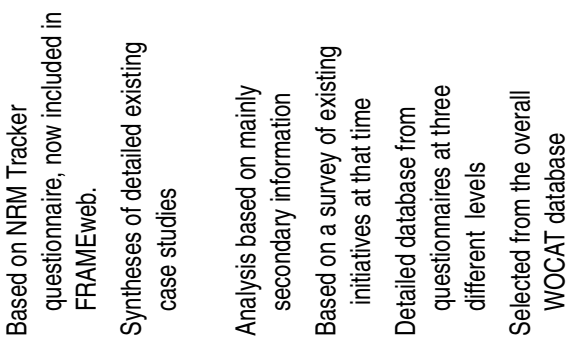

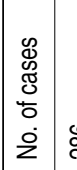

寒

$$
\text { (2) }
$$

잉

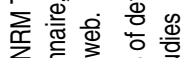

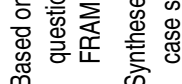

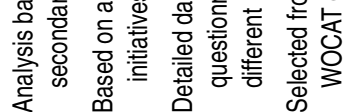

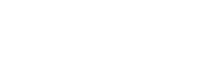

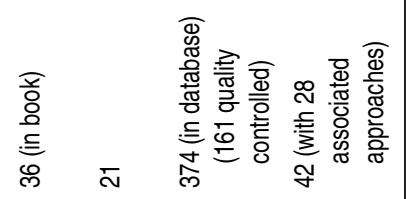

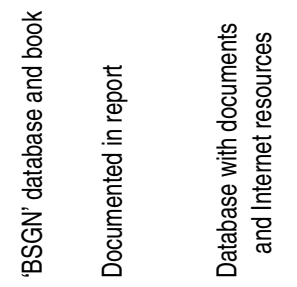

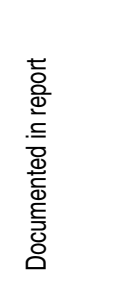

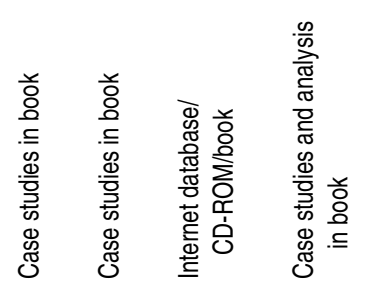

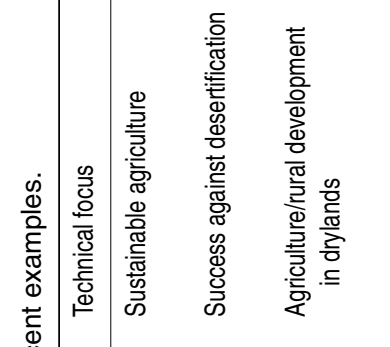

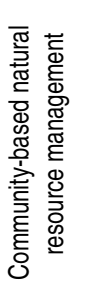

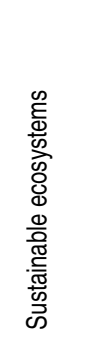

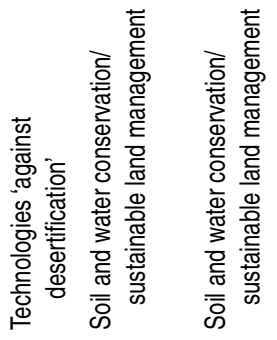

윤

증

敢

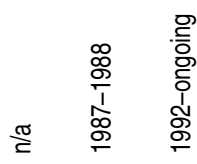

$\frac{\overline{0}}{\bar{O}}$

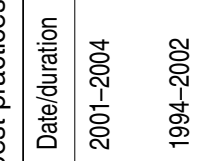

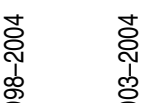

ષ્ণ

芯 嵒

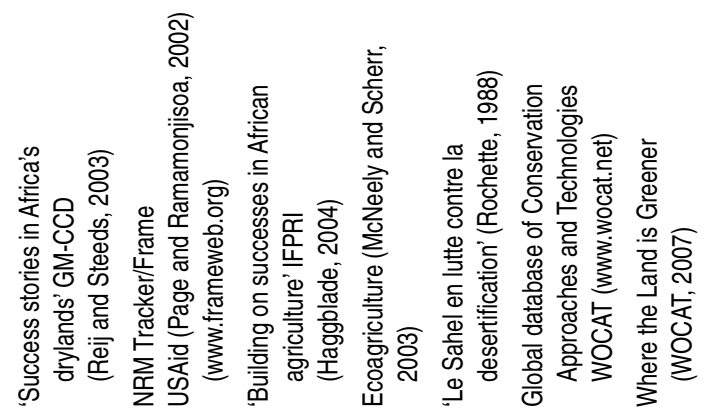




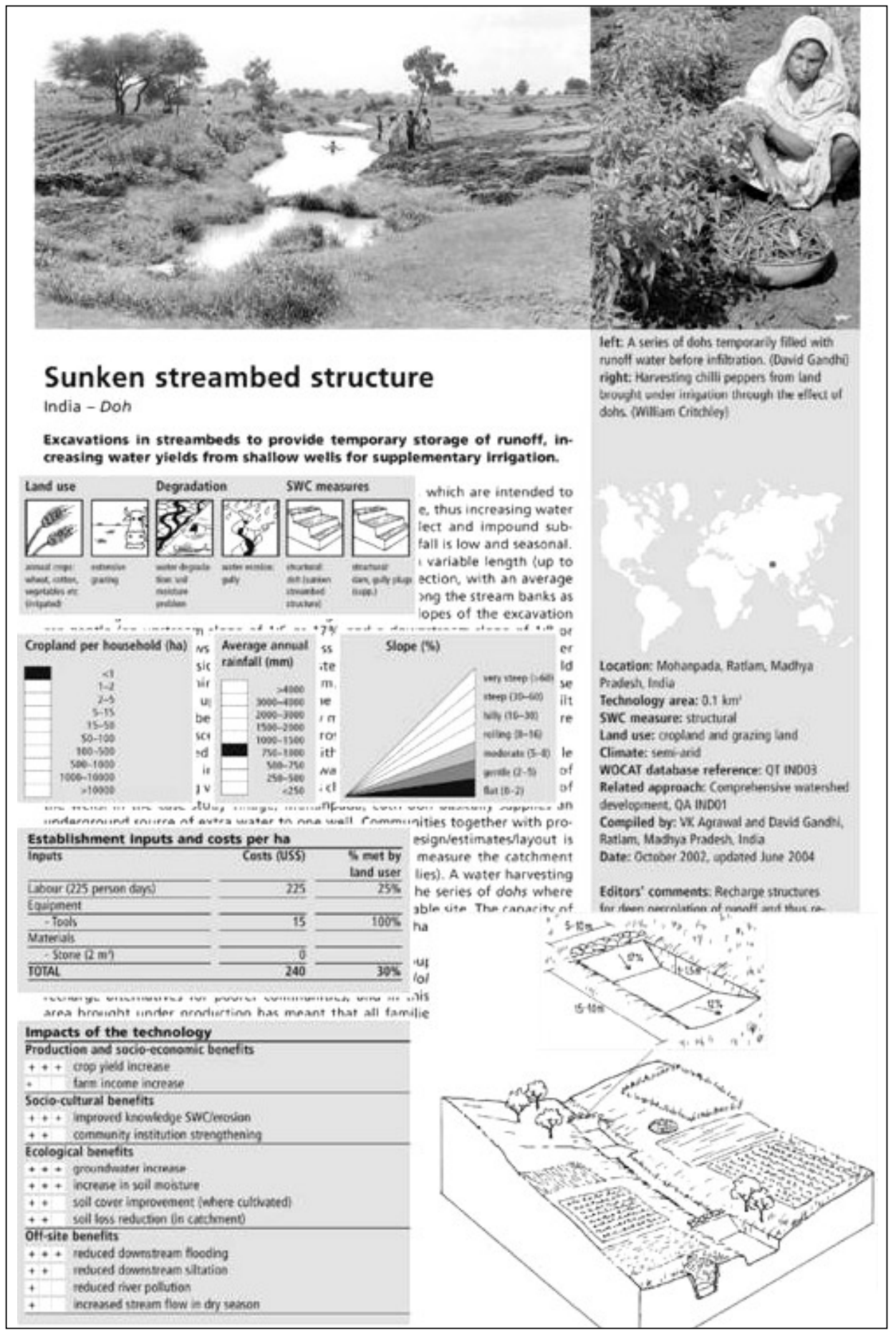

Fig. 9.2. Selected aspects collated to illustrate the layout of four pages of the doh technology from India (WOCAT, 2007) Various aspects are superimposed on the first (mainly) text page to give an idea of the range of information presented. See WOCAT, 2007 for full examples of the four-page layouts. 
Box 9.4. The technology: sunken streambed structure (Doh), Madhya Pradesh, India (WOCAT, 2007)

A doh is a rectangular excavation in a seasonal streambed, which is intended to capture and hold runoff to enhance groundwater recharge, thus increasing water for irrigation from nearby shallow wells. It also collects and impounds subsurface flow. Dohs are built in semi-arid areas where rainfall is low and seasonal. The dimension of a typical doh is 1.0-1.5 m deep with variable length (up to $40 \mathrm{~m}$ ) and width (up to $10 \mathrm{~m}$ ), depending on streambed section, with an average capacity of $400 \mathrm{~m}^{3}$. The removed material is deposited along the stream banks as a barrier against siltation from surrounding areas. The slopes of the excavation are gentle, so that water flows into it and excess water out again, carrying silt rather than depositing it. The sides, however, are steep, to increase capacity - but would benefit from stone pitching for stability. A silt trap comprising a line of loose boulders is constructed upstream across the streambeds. Dohs are generally built in sequence. They may be as close as a few metres apart. Bends in the stream are avoided as these are susceptible to bank erosion. The technology is used in conjunction with shallow wells (odees), which enable farmers to utilize the increased groundwater supply for irrigation of annual crops - including vegetables such as chilli peppers. Water is pumped out of the wells. In the case of the case study village, each doh basically supplies an underground source of extra water to one well. Site selection is carried out by communities together with project staff, and then detailed design/estimates/layout is done with project technical assistance. The catchment area is treated with small stone gully 'plugs'. A tank (small reservoir or dam) may be excavated above a series of dohs where this is justified by a sufficiently large catchment area and a suitable site. The capacity of the tank at Mohanpada village is around $600 \mathrm{~m}^{3}$ and this also has a positive impact on groundwater recharge. Maintenance is agreed through user group meetings: manual desilting is planned as is the repair of gully plugs. In this village, the extra area under production means that all families now have access to water for irrigation.

Box 9.5. The approach: comprehensive watershed development (WOCAT, 2007)

The 'comprehensive watershed development approach' is intended to ensure sustainability of development interventions. The objectives are to create a sense of ownership amongst users; to ensure that users manage resources well, both during and after intervention; to benefit vulnerable community sections; and, finally, to involve the community in the planning, implementation and management of the interventions. This is achieved through the following methods: awareness generation within the community through exposure visits; street theatre and video shows; formation and capacity building of village-level institutions; microplanning (under a 'village development plan') using PRAs; cost and benefit sharing; ensuring usufructuary rights (formation of users' groups and negotiation with government for rights to produce from common land); and, lastly, the involvement of NGOs with government staff for better communication with the community. The stages of implementation are as follows: awareness generation; group formation; microplanning; participatory execution and cost sharing (although 75-90\% of the work is paid for in cash under this approach); initiation of processes regarding user rights; and, finally, management by users' groups, including maintenance, distribution of benefits and conflict resolution. The role of the participants is briefly as follows: government staff provide technical and financial support and assistance to gain user rights; NGOs are responsible for awareness generation and mobilization, capacity building of village-level institutions and the community, as well as negotiation with government; local government oversees permission regarding users' rights; the village committee creates and implements the village development plan and oversees users' groups, which then plan, implement and manage common resources; the village assembly identifies beneficiaries and gives support to the village watershed development committee. This approach is supported by an external international donor, DANIDA of Denmark.

analyses the 28 approaches underpinning the case studies (WOCAT, 2007). The documented approaches range from examples of selfmobilization to those characterized by heavy subsidies and strong external technical support. Where the questionnaire has been completed to describe a tradition, a number of the questions are difficult to answer or irrelevant. In these cases, the technology case studies stand alone. Only dedicated research can help to unravel the circumstances leading to the evolution of these traditional technologies. Of the 28 approaches 
presented in the book, 20 are basically allied to projects/programmes, and the other eight are descriptive of how spontaneous spread has occurred outside a structured campaign. One of these eight describes a tradition - the remaining seven refer to recent developments.

Without exception, the sample constitutes approaches that are viewed as being positive or at least 'promising'. Thus, the analysis opens a window on denominators of success. Some of these denominators are common to many approaches, others are situation-specific. Within the sample, there is a bias towards those approaches that have underpinned relatively successful technologies, and particularly technologies which are remedial (through mitigation or rehabilitation of erosion problems) rather than preventive (helping maintain sustainable systems).

The current thinking in rural development including sustainable land management emphasizes the importance of participation of land users in all aspects of the project cycle and is reflected in new terminology. Several of the approaches reported here have the word 'participation' either specified in their titles or mentioned in their brief description, yet only one has it highlighted under objectives. While the names and objectives of many projects genuinely try to reflect the new, end-of-century, approach, it may well be that some are using terminology because it is 'developmentally correct' or even necessary to attract funding.

A search through the objectives of the various approaches brings up an interesting array of aims, several of which are broader than just targeting better soil and water conservation. Many of the case studies involve SWC as just one element - a subset - of a wider rural development programme. A common general pattern emerges regarding objectives, actions and implementation arrangements, however. This can be represented as follows:

- Goals: environmental improvement and poverty alleviation.

- Through: improved plant and livestock production, requiring conservation of specific resources.

- Based on: raised awareness, a sense of ownership, gender equality and improved governance.

- Combining: joint efforts of various actors with strengthened institutions.
Looking at the most recent trends, we can see a new set of objectives emerging in SLM interventions. These new objectives address rapidly emerging global environmental concerns, particularly those of mitigating climate change (hence carbon sequestration, through biomass and increased soil organic matter levels), above and below ground biodiversity, and water (hence ecosystem functioning as well as water-use efficiency under rainfed and irrigated agriculture). There are some indicators of future trends in the cases analysed. It is likely that increasing attention will be paid to addressing SLM concerns through new marketing opportunities of which fair trade coffee from Costa Rica and 'Vinatura' environmentally friendly wine from Switzerland are examples from the case studies. Pilot schemes promoting payment/compensation for ecosystem services are almost certainly forerunners for a new breed of programme. These typically comprise compensation to land users in upland areas for maintaining vegetation in catchment areas, from industries, urban dwellers or farmers downstream, to ensure water supply and mitigate damage from floods and landslides. Ecotourism is already popular in parts of the world and 'agroecotourism' is following cautiously in its environmental footsteps.

It is revealing to look through the strengths of the various approaches, as recorded by SLM specialists closely associated with the related project (where the approach is project-based). What tend to be reiterated in these 'strengths' are several of the objectives stated earlier. The documented weaknesses of the approaches are at least as important to this analysis as their strengths. These include:

- The period of intervention and funding need to be of significant duration.

- The problem of participatory approaches being very demanding on human resources.

- The need for more training.

- External material support given to land users having the effect of being temporary 'bribes'.

- Lack of support or recognition from outside - where the 'approach' describes a tradition or spontaneous spread of a technology.

Genuine participation is related to the level of input (labour, materials and intellectual) provided voluntarily by the land users/beneficiaries. Thus, one key aspect of any approach is the extent to 
which the approach includes subsidies and support for existing/local efforts and resources to implement SLM Technologies, and how far this might then influence further, and future, spread. If a high level of material subsidy is given, spontaneous uptake will be unlikely, as people will expect to receive continued support. The majority of external material support or subsidies provided by projects take the form of minor material inputs, such as seeds, tools and fertilizer, and payment for labour. In 15 out of the 20 project/ programme-based approaches, however, there were low or negligible levels of inputs. In fact, five of these 15 cases provided no external material support to land users at all, implying full cost borne - and thus full commitment - by land users.

The cases from the developed countries in Europe - Switzerland and the UK - stand apart. Here, there are heavy government subsidies in general for agriculture, although the current tendency is to decouple these from production and link farm-level support instead to environmental protection and stewardship. The triple bottom line case from Australia, however, does not benefit from subsidies for sugarcane, which is not protected from world market prices: environmental protection has been achieved despite the relatively low prices and lack of external support. These same global market prices can have a direct influence on land management in other situations. In Kenya, the high price of coffee in the 1970s stimulated and helped pay for the construction of terracing systems amongst small-scale producers. Most have been kept up, despite a later slump. In Costa Rica, however, the international drop in coffee prices over the last 2 decades has had a negative impact on spontaneous uptake of the 'café arbolado' system.

Taking all the 20 project-based case studies together, it is striking that - calculating the average proportions of funding sources - a quarter of the contributions are from local communities and nearly one-sixth from national governments. The international community provides, on average, just over half (55\%). Outside donors are important investors in these successful examples of SLM interventions - but not at as high a level as might have been expected. The level of community/ individual contributions and their 'buy-in' to the initiatives is generally impressive, considering that many of the projects cover very poor areas.

Strong community involvement is highlighted further by the fact that nearly half of the projects/programmes claim that the choice of technology was principally the choice of the land users (either alone or supported in their choice by SLM specialists). The final piece of evidence regarding ownership of the process is that the actual design of the approach shows significant international expert input in less than half of the project/programme approaches. The others were designed by national and local experts.

Broadly speaking, there are three forms of extension and training used by the projects analysed:

- First, that which could be termed the 'multiple strategy'. This is what is adopted by the majority of the project/programme-based approaches. It includes several or all of the following: awareness-raising, training workshops and seminars around specific themes, exposure visits, hands-on training, and the use of demonstration plots.

- The second is based on informal farmer-tofarmer extension and exchange of ideas.

- The third is centred on the use of trained 'local promoters'. These are basically local farmers who are trained to become facilitators/ extension workers under a project.

Whether land-use rights affect the spread of SLM Technologies - and if so, in what way - is one of the most interesting issues here. A common assumption is that private ownership of land equals security, thus giving the owner an incentive to invest. This is confirmed by at least two case studies reviewed - examples from Nicaragua and Kenya. The issue here, however, seems to be security of access rather than titled ownership, the former providing as great an incentive as the latter. Truly open access regimes are rare, but there are many examples of where user rights are confused and ambiguous. Under such conditions, there is the double dilemma of nobody accepting responsibility and no one being prepared to invest in the land. The potential for 'tragedy of the commons' scenarios is an active and present danger. That scenario, which depicts a free-for-all descent into land degradation, needs to be countenanced. 
The majority of projects are involved in monitoring and evaluation (M\&E) (Fig. 9.3). This, however, refers mainly to the basic requirements imposed by governments or funding agencies: financial indicators and recording physical targets of dubious value (e.g. 'running kilometres' of conservation structures built; number of tree seedlings raised in nurseries). There is little or no mention of truly 'participatory' M\&E, with only five of the 20 project-based cases being 'self-mobilized' to carry out monitoring. Apparently, even the most forward-thinking projects have not ventured so far into the realms of participation that they open up that complex set of issues, which involve such questions as: what is meaningful to whom to measure? Who measures what? Who records the results? Who interprets the results and uses them?

\section{Technologies: their Contribution to Land and Water Management}

The various case studies in Where the Land is Greener show bright spots (or 'green spots' as they are referred to in the book) covering a broad scope of improved land management activities. These include soil and water conservation and water harvesting, ranging from smallscale subsistence to large-scale commercial farming and from arid to humid climates all over the world.

According to the WOCAT classification system (Liniger et al., 2002), SLM Technologies are subdivided into the following conservation measures: management, agronomic, vegetative and structural, and combinations of these. Each of these conservation measures is split up into subcategories. The main criteria are the appearance, the materials and the management involved in the technology (see Box 9.6).

In Where the Land is Greener (WOCAT, 2007), 42 case studies on SLM Technologies are presented and analysed and some of the key issues are summarized in the following.

With regard to local impacts of SLM interventions, medium to high impact was reported regarding:

- Reduction of soil erosion: in almost $90 \%$ of cases (37/42).

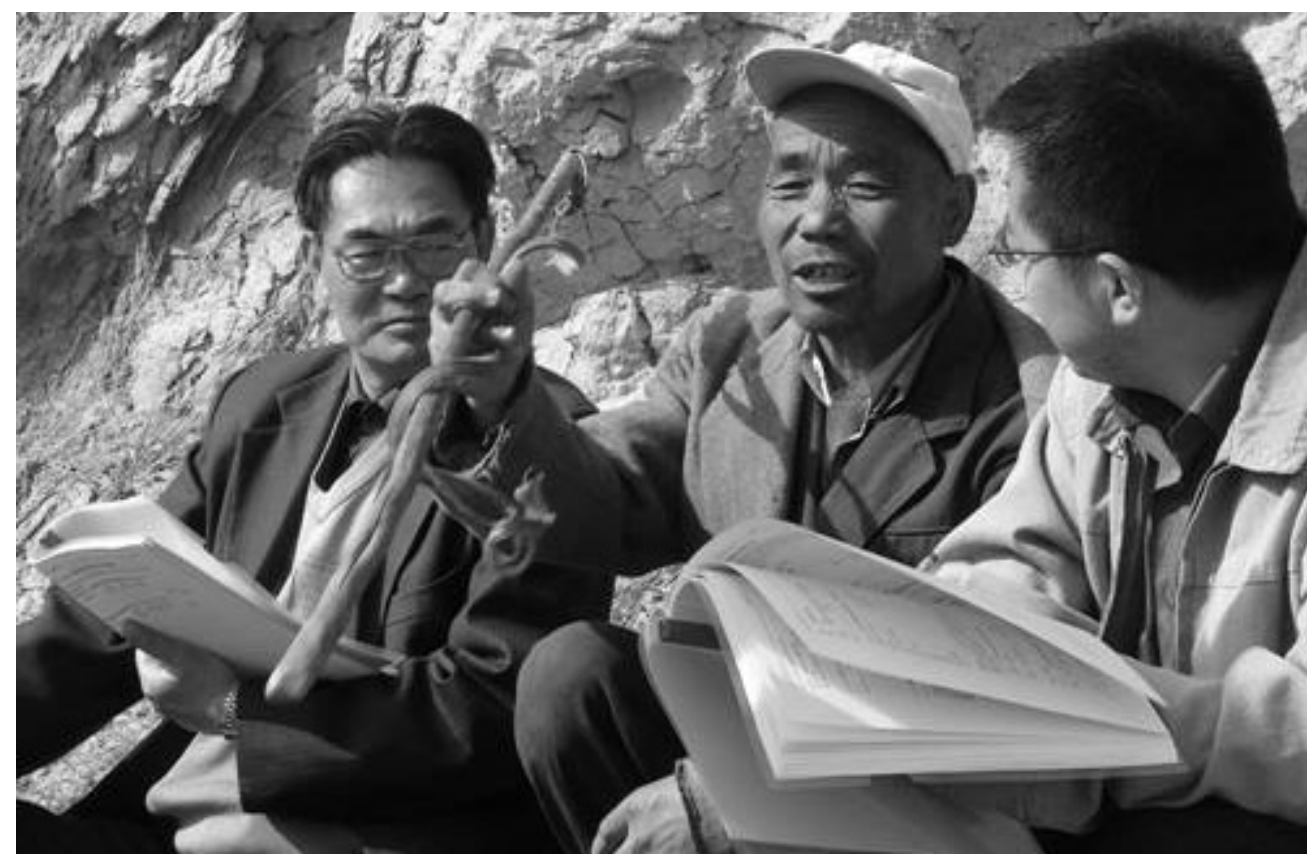

Fig. 9.3. A farmer, together with specialists, evaluates the pros and cons of different land management practices to protect a small dam from siltation. Loess Plateau, China (Photo: H.P. Liniger). 
Box 9.6. WOCAT major categories of SLM Technologies (Linger et al., 2002)

- Management measures (such as land-use change, area closure, rotational grazing, etc.) involve a fundamental change in land use; involve no agronomic and structural measures; often result in improved vegetative cover and often reduce the intensity of use.

- Agronomic measures (such as mixed cropping, contour cultivation, mulching, etc.) are usually associated with annual crops; are repeated routinely each season or in a rotational sequence; are of short duration and not permanent; do not lead to changes in slope profile; are normally not zoned and are normally independent of slope.

- Vegetative measures (such as grass strips, hedge barriers, windbreaks, etc.) involve the use of perennial grasses, shrubs or trees; are of long duration; often lead to a change in slope profile; are often zoned on the contour or at right angles to wind direction and are often spaced according to slope:

- Structural measures (such as terraces, banks, bunds, constructions, palisades, etc.) often lead to a change in slope profile; are of long duration or permanent; are carried out primarily to control runoff, wind velocity and erosion; often require substantial inputs of labour or money when first installed; are often zoned on the contour/against wind direction; are often spaced according to slope and involve major earth movements and/or construction with wood, stone, concrete, etc.

- Combinations are possible and common.

- Soil moisture improvement: in over $71 \%$ of cases (30/42).

- Soil cover improvements: in $67 \%$ of the cases (28/42).

- Yield increase for crops in $60 \%$ (25/42); for fodder production in almost half (20/42) and wood production in $17 \%$ of the cases $(7 / 42)$.

Perceived benefits in relation to costs have also been investigated (Fig. 9.4). In the short term (within 3 years), $63 \%$ of the cases reported that the benefits outweighed both the establishment and maintenance costs. Those cases have a rapid payback and are thus worthwhile for every land user to invest in, as the returns are immediate. This applied to all water-harvesting cases as well as to those where the measures were aimed directly at fertility improvements (manuring and composting). One quarter of the cases showed short-term negative returns in relation to establishment, but positive returns in relation to maintenance. These often require some support by projects, by the government or by the communities for a kick-start (e.g. for terraces). The $15 \%$ of the cases with negative returns from both investment and maintenance (six examples) would, however, be unlikely to be taken up by small-scale subsistence farmers, unless they were rewarded with incentives. These technologies inevitably require long-term external support if they are to be promoted and could only be justified for supplementary reasons, such as off-site benefits.
Whereas a number of important aspects need to be considered for the analysis of suitable SLM Technologies, such as the natural environment in which they are applied (e.g. climate, slope, soils) and the human environment (e.g. subsistence/commercial farming, land size and land-use rights), the focus of this chapter is on water issues.

By definition, all SLM Technologies function in relation to water - usually in regard to control of runoff and increase of infiltration, and, as a result, an increase in water stored in the soil. Soil erosion by water is the most frequently addressed degradation type, and the following principal SLM functions principles related to water can be differentiated:

- Diverting/draining runoff and run-on.

- Impeding runoff.

- Retaining runoff/preventing runoff.

- Collecting and trapping runoff (water harvesting).

This illustrates the importance of managing water flow on the soil surface, its drainage and its infiltration into the topsoil. The overall impact is reflected in the amount of water being stored in the soil, recharging the ground water and feeding springs and rivers.

Some technologies are more explicitly related to drainage, and some specifically designed to harvest water. Nearly all (88\%) of the 42 SLM technology cases indicated an increase in soil 


\section{Short-term cost and benefits}

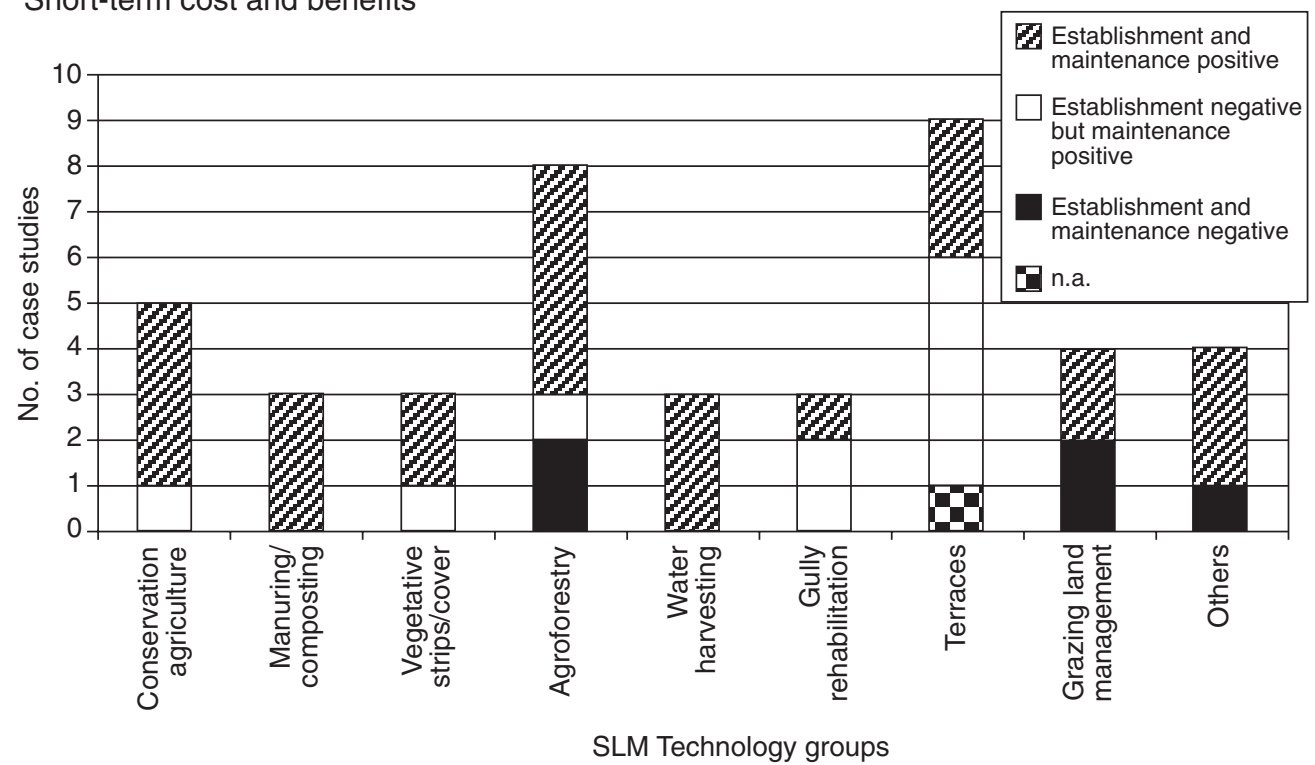

Fig. 9.4. Establishment and maintenance costs over the short term for the different SLM Technology groups (WOCAT, 2007).

moisture (Fig. 9.5). In $71 \%$ of all cases, improvement was rated as 'medium' or 'high'. In onethird of the cases, drainage was said to have improved. Reduced water loss through runoff and increased water infiltration and storage in the soil were consistently perceived as leading to greater water availability. Cases from dry areas report seasonal water loss in the order of $15-20 \%$ due to surface runoff. Additionally, the potential of reducing evaporation from the soil, especially in drier environments, where $40-70 \%$ of the rainfall can be lost, has been described clearly in examples of 'conservation agriculture'. The combined water loss through runoff and evaporation often leaves less than half of the rainfall - or irrigated water - available for crops or other vegetation. This clearly demonstrates the need for, and potential of, SLM. Terraces, rainfed as well as irrigated, also have a profound impact on water. Rainfed terraces generally provide for storage of rainfall through a raised 'lip' and are often designed to discharge excess runoff through a drainage system. Examples of this are the 'rainfed paddy rice terraces' in the Philippines and the 'Zhuanglang loess terraces' in China (WOCAT, 2007).
The way that SWC technologies manage water (controlling splash, controlling dispersed and concentrated runoff, improving infiltration or improving the fertility, etc.) provides the major challenge for the identification and promotion of bright spots. Depending on the climate, two major categories can be differentiated.

In humid environments soil erosion is a common cause of land degradation and soil fertility decline. The implication is that conservation measures have to solve the problem of excess water and its safe drainage either through the soil profile or on the surface. Here, the main aim is to reduce the rapid runoff that causes sheet, rill and gully erosion on site and flooding, sedimentation and pollution of rivers and water reservoirs off site (downstream).

The case studies illustrate several vegetative measures. These include grass strips in the Philippines and South Africa, permanent green cover either by grasses, as in the Swiss vineyards, or through agroforestry systems, as in eastern Africa, Latin America, the Philippines and central Asia. Through terracing of steep slopes in wet conditions, these hillsides have been turned into productive systems - for 


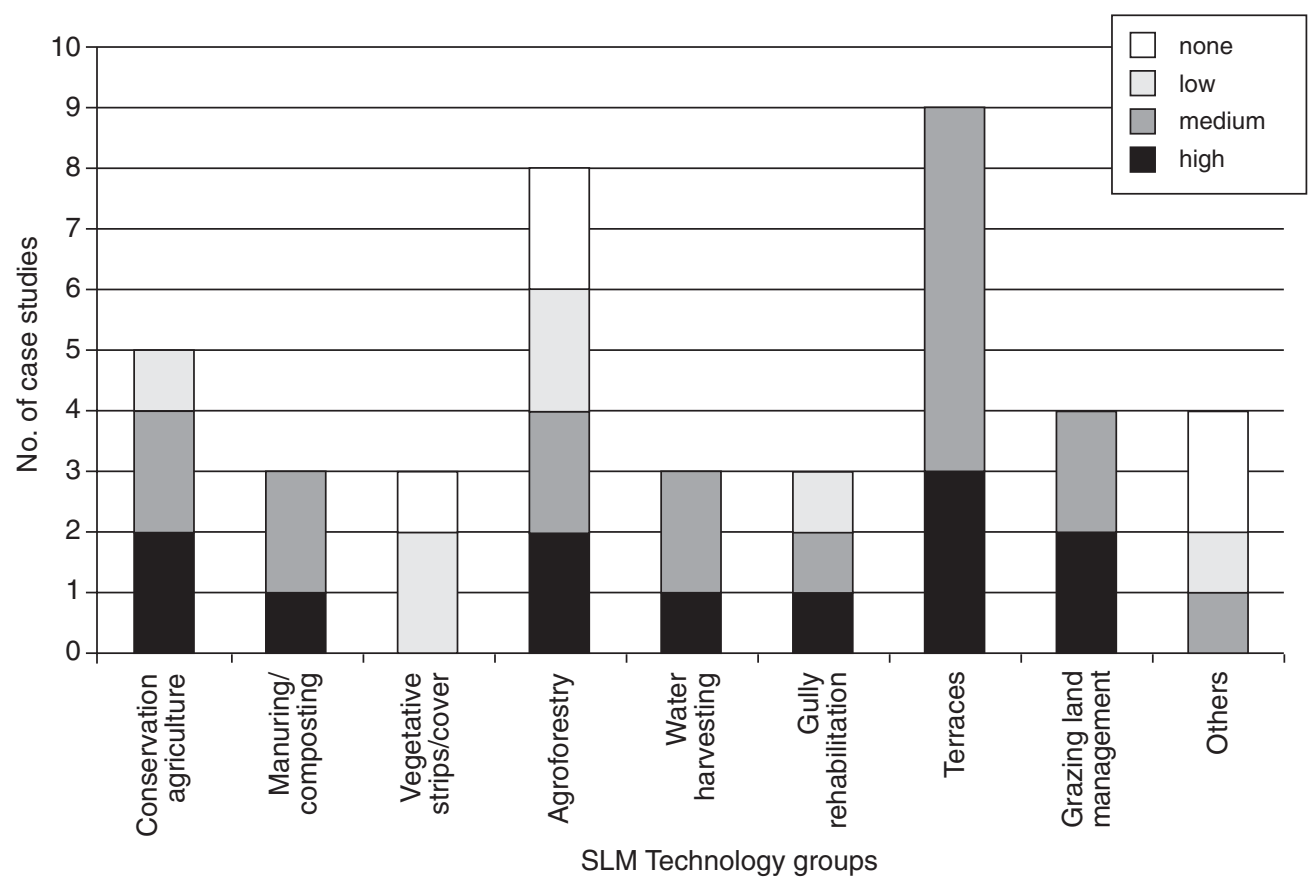

Fig. 9.5. Increase of soil moisture within the different SLM Technology groups (WOCAT, 2007).

example, for paddy rice production in Nepal. Finally, there are specific technologies to cope with gully erosion, where the combination with other measures upstream is essential for the functioning of these technologies in the drainage channels or riverbeds (as illustrated in the case of gully control and catchment protection in Bolivia). These practices in humid and subhumid environments have helped to prevent degradation and to maintain or enhance soil fertility in degradation-prone areas. These need also to be seen as bright spots.

In semi-arid and arid regions, the main focus is on water conservation and improved wateruse efficiency, for example through in situ accumulation of soil moisture and reduction of the water losses by runoff and direct soil evaporation, or through water harvesting. In Where the Land is Greener the following examples are presented:

- In situ conservation: several "conservation agriculture' technologies are presented, which range from small-scale farming conditions in Kenya to medium-scale in Morocco and large-scale commercial farming in Australia. All of these fall under the category of agronomic measures - the principles of 'conservation agriculture' are that soil disturbance is minimal, direct drilling is practised, soil is covered (for as long as possible) by crops or mulch and crop rotation is practised.

- Water-harvesting technologies: these function by collecting and concentrating rainfall runoff for crop production - or for improving the performance of grass and trees - in dry areas where moisture deficit is the primary limiting factor. As an example the doh technology is presented (see Boxes 9.4 and 9.5, and Fig. 9.2), as well as planting pits collecting water from the adjacent areas where infiltration is hindered due to surface crusting (planting pits - zai and tassa from West Africa) or the v-shaped furrow enhanced system that collects water for the establishment of olive trees in Syria. The last three systems work 
through microcatchments ranging from less than one to several square metres, where water is harvested and concentrated for the production of grains or the establishment of trees.

Under climates characterized by prolonged dry spells, water conservation through reduced evaporation loss and water harvesting has great potential to improve agricultural production and reduce the risk of crop failure. This is true under rainfed agriculture, as well as reducing water demand under irrigation. Many of the documented case studies show that they are very well adapted to the local environment and fulfil multiple functions. They thus often involve combined measures, for example structures to collect water as well as agronomic measures to reduce runoff and evaporation losses.

The main finding from the analysis of these cases is that, through improved water management, the amount of water for the crops, grasses or trees is increased, and this results in immediate benefits for the farmers.
Off-site effects of bright spots are very seldom documented and thus represent 'a great unknown'. Figure 9.6 presents a summary of the perceived off-site (generally 'downstream') advantages and disadvantages of the technologies described in the case studies. The most striking water-related, off-site benefit is the reduced downstream flooding and siltation reported in three-quarters of the case studies. Around half indicated a high to medium impact. Just fewer than half $(43 \%)$ indicated reduced river pollution, and about one-third noted increased river/stream flow in the dry season. The information - derived from SLM specialists working with land users - has, however, seldom been quantified (Fig. 9.7). There are also a few off-site disadvantages mentioned; reduced overall river flow was reported in four (of the 42) cases, though the impact was assessed as 'low' in three cases. These cases referred to situations where terracing, and additional irrigation and water-harvesting structures, reduced flows to downstream zones.

\section{Off-site benefits}

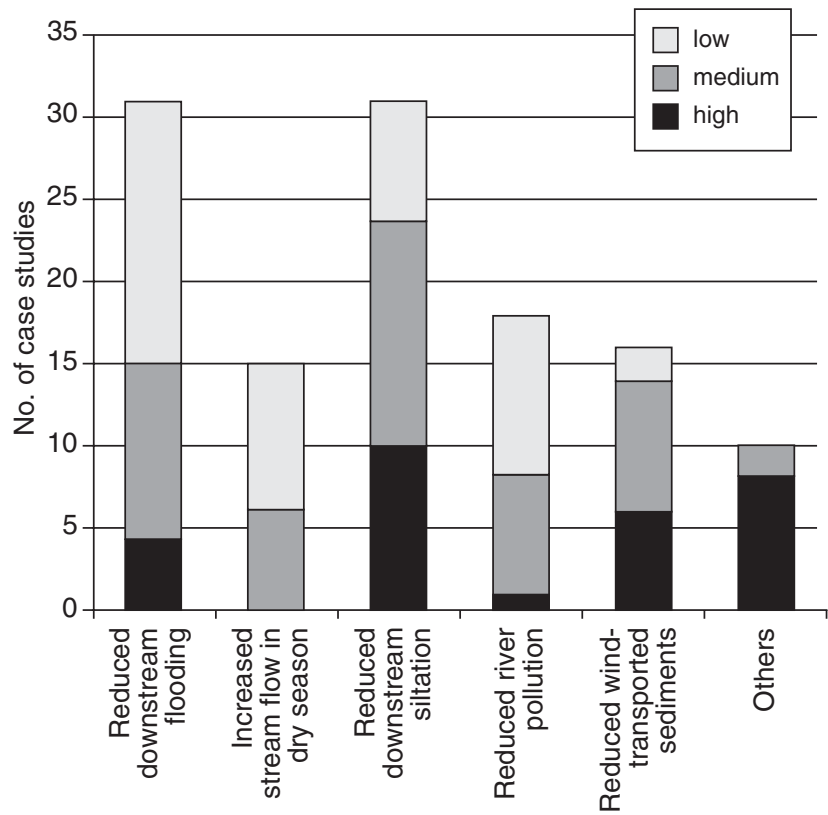

Off-site disadvantages

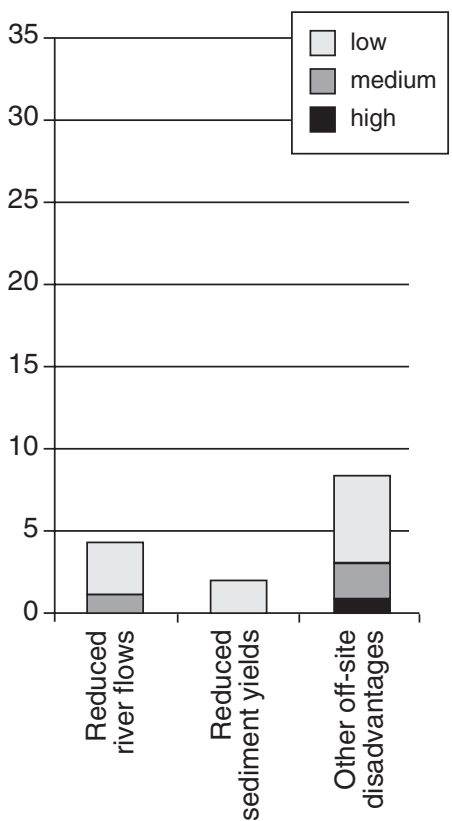

Fig. 9.6. Off-site benefits and disadvantages of SLM Technologies (WOCAT, 2007). 


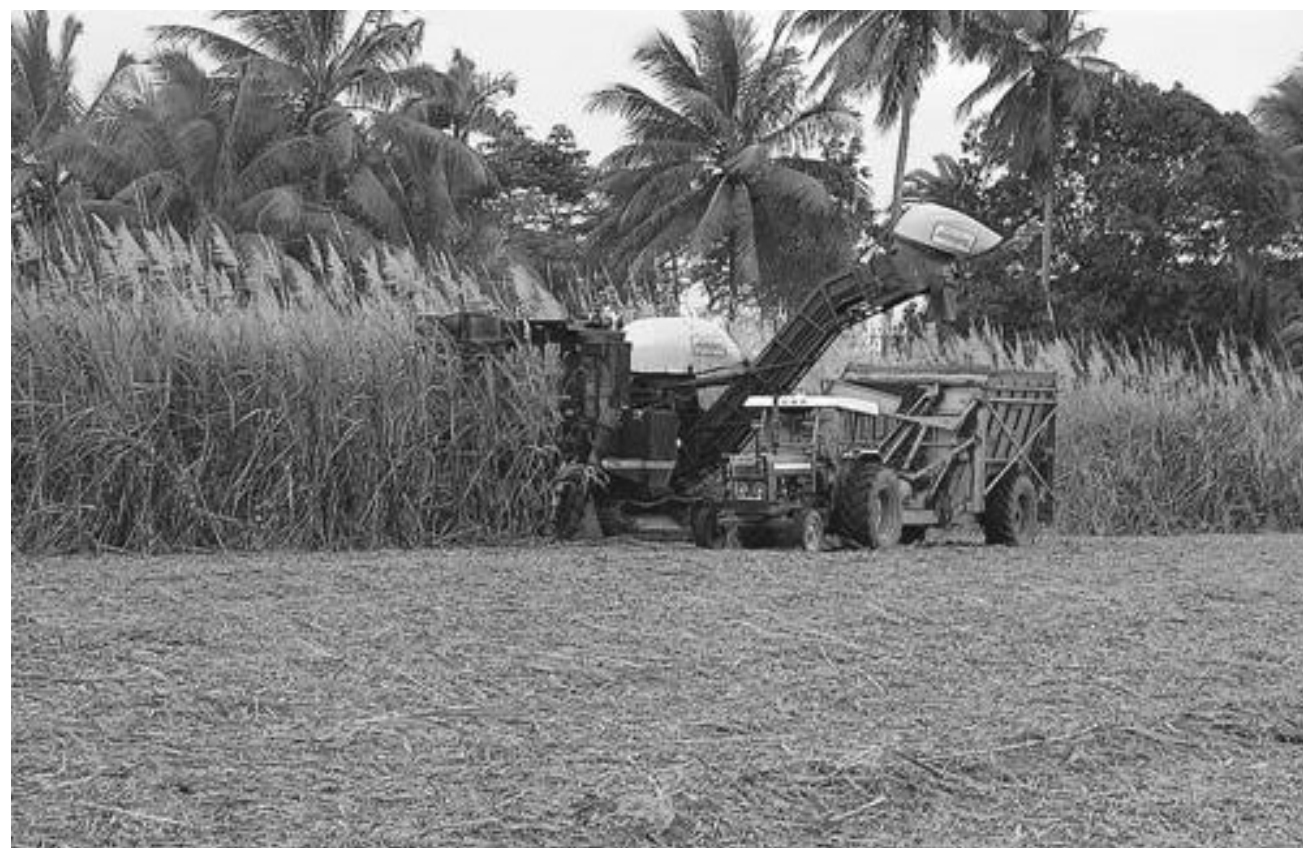

Fig. 9.7. The 'green cane trash blanket' is a practice from North Queensland in Australia. Non-burnt cane is harvested and the trash is left on the fields. Apart from the on-site benefits of increased organic matter, improved soil structure and reduced erosion, off-site benefits are crucial, as sediment lost from the coastal sugarcane strip is washed out to the sea and damages the growing coral of the Great Barrier Reef. Far north Queensland, Australia (Photo: H.P. Liniger).

\section{WOCAT: the Lessons Learned So Far and the Need to Address the Knowledge Gaps}

From the experiences presented in Where the Land is Greener, three aspects are highlighted and the conclusions, as well as the derived policy points, are presented (Boxes 9.7, 9.8 and 9.9). Given that they are based on a globallevel analysis, they require fine-tuning and more explicit formulation to reflect specific national and regional solutions. This global overview provides a 'model' that could be used for comprehensive documentation and analysis of experiences, leading to refined policy guidelines at the national and regional levels.

\section{The link between water and soil}

The case studies analysed clearly demonstrate the importance of good land management and its impact on water resources on site in terms of making more water available for crops, grasses and trees, as well as off site by reducing the negative impacts of flooding or seasonal decreased water availability. In terms of improved water management, land use and soil and water conservation play a crucial role. Both water quality and quantity depend heavily on land management. Water management cannot be separated from land use. Thus, there is great potential to mitigate or prevent further deterioration of water resources, be this in terms of quality or quantity. Efforts to expand bright spots in sustainable land management need to be seen as a necessary investment towards mitigating global water crises and conflicts over water. Water and soil management are inseparably linked (Fig. 9.8).

\section{Improved knowledge management - capitalizing on scattered experiences}

Worldwide, there are numerous positive experiences derived from investments in soil and water 
Box 9.7. Points for policy makers: general and water-related (selected from WOCAT, 2007):

- Promotion of SLM Technologies that lead to the improved management of natural resources - soil, water and vegetation - has the potential not only to reduce land degradation but also to address simultaneously global concerns of water scarcity, land-use conflicts, climate change (through carbon sequestration), biodiversity conservation and poverty alleviation. Continued, sustained investments in optimizing and adapting technologies to their specific environments as well as recognizing innovative improvements are needed.

- In dry areas, investments in water harvesting and improved water-use efficiency, combined with improved soil fertility management, should be emphasized to increase production, reduce the risk of crop failure and lower the demand for irrigation water.

- In humid areas, long-term investments are required to maintain soil fertility and minimize on-site and off-site damage caused by soil erosion, as the impacts on production and conservation may only accrue in the medium and long term.

Box 9.8. Points for policy makers: monitoring, evaluation and documentation (selected from WOCAT, 2007)

- Concerted efforts to standardize documentation and evaluation of SLM Technologies and approaches are needed and fully justified, especially in the light of the billions of dollars spent annually on implementation.

- Monitoring and evaluation (M\&E) in SLM projects/programmes must be improved. It needs to do more than just monitor the timely delivery of project outputs; it should also evaluate whether the expected environmental and development benefits have been realized in a cost-effective manner.

- Land users have to be involved as key actors in M\&E activities: their judgment of the pros and cons of SLM interventions is crucial.

- More investment in training and capacity building is needed for objective and unbiased M\&E, for impact assessment and to improve skills in knowledge management, including the dissemination and use of information.

Box 9.9. Points for policy makers: the need for better research (selected from WOCAT, 2007)

- Technologies and associated approaches need to be flexible and responsive to changing complex ecological and socio-economic environments.

- An urgent and specific area for further investigation and research is the quantification and valuation of the ecological, social and economic impacts of SLM, both on site and off site, including the development of methods for the valuation of ecosystem services.

- SLM research should seek to incorporate land users, scientists from different disciplines and decision makers. A continuous feedback mechanism is needed to ensure the active participation of these stakeholders.

- Researchers need to take a more active role in further developing tools and methods for knowledge exchange and improved decision support.

conservation (SWC) that contribute to sustainable land management (SLM). These counter the prevailing and pessimistic view that land and environmental degradation is inevitable and continuous. Apart from the cases documented through WOCAT (and elsewhere), the vast body of knowledge and wealth of experience in SLM made either by projects or through innovations and initiatives by the land users themselves remains scattered and localized. There is still a rich, untapped SLM diversity that is not readily available to land users, those who advise them, or planners and decision makers. Thus the basis for sound decision making is lacking, mistakes are being repeated, and the wheel is being reinvented.

Monitoring and evaluation, especially of the technical efficiency and cost-effectiveness of SLM Technologies and Approaches, are weak spots in many, if not most, projects. Likewise, 


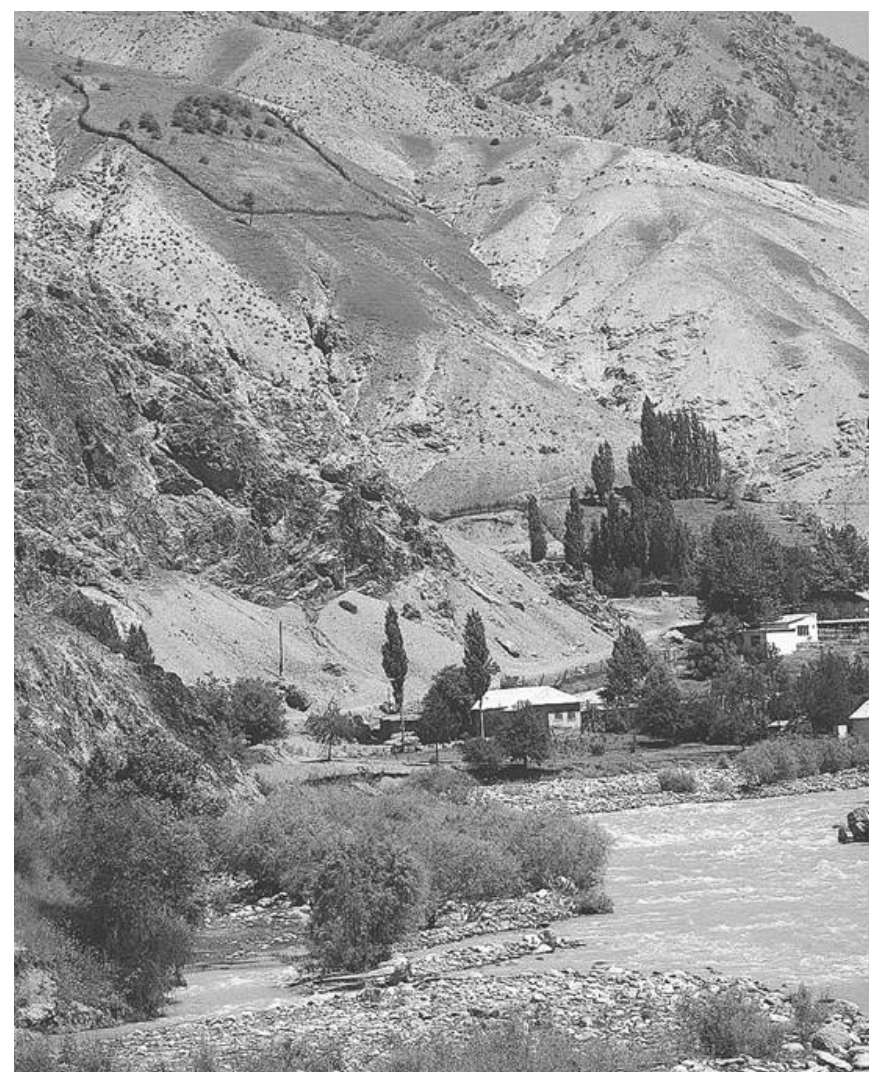

Fig. 9.8. Land degradation due to overgrazing contrasted with soil and water conservation within a fencedoff area with terraces and fruit trees and grasses for haymaking. On-site available water for vegetation and off-site water quality, as well as the flow regime (floods, low flows), are affected when significant areas are treated in this way. Varzob valley, Tajikistan (Photo: H.P. Liniger).

traditional land-use systems and local land management innovations are rarely documented and assessed for their conservation efficacy.

The WOCAT tools provide a unique standardized method for the comprehensive documentation, monitoring, evaluation and dissemination of SLM knowledge from various sources including land users, SLM specialists and researchers from different disciplines.

\section{The need for training and capacity building and research}

By using the standardized WOCAT framework, it has been possible to expose a number of key misconceptions, biases and knowledge gaps common to SLM specialists in different countries. SLM specialists need to critically review the often fragmented knowledge, to identify gaps and contradictions, to question and evaluate current perceptions and field experiences. In so doing, locally appropriate ways of achieving the end objective of sustainable and productive land management can be achieved (Liniger et al., 2004).

This helps to question and analyse personal perceptions and field experience, to be selfcritical and to expose knowledge gaps, misconceptions and biases. This may be demanding on the specialists to expose weaknesses, but it turns into a strength as they 'dare to share' and thereby improve their knowledge. This invites others to contribute and assist in the search for 
locally appropriate ways of achieving sustainable land management. Thus, thorough selfevaluation enhances capacity (Fig. 9.9).

In order to face the challenge of sustainable land management where solutions need to be fine-tuned to very specific natural and human environments, land users and SLM specialists need to form working teams with strong partnership at the local level, but also at the regional level and even internationally.

To adapt land-use systems optimally to the natural and human environment there is a need not only to develop capacity by learning about other SLM experiences but also to enhance capacity based on personal experience. The WOCAT experience shows that even where people are involved in projects, knowledge is still often fragmented.

Although WOCAT was not designed as a research programme, it has shown that collaboration between applied research and implementation is crucial for the success of documentation and exchange. The requisite contributions of research towards a better understanding of degradation and improved implementation of good land management practices are to:
- Assist SLM specialists in the documentation and evaluation of existing SLM knowledge, be it traditional/indigenous or newly introduced.

- Identify and address important gaps/needs, e.g. cost/benefits and impacts of land use (ecological, social, economic).

- Search for solutions and improvements based on land users' experiences.

- Assess impacts of land use on natural resources and identify key indicators and threshold values.

- Document agrobiodiversity.

- Assess degradation and good land use (WOCAT map tool combined with remote sensing, surveys, etc).

- Contribute to upscaling and 'downscaling' between local, regional and global levels.

In order to address these gaps, WOCAT has initiated research in collaboration with EUfunded projects and the Swiss National Centre of Competence in Research (NCCR) NorthSouth (Hurni et al., 2005). The main focus is on the impact assessment and monitoring of SLM, locally and regionally, as well as the wider dissemination of suitable SLM measures.

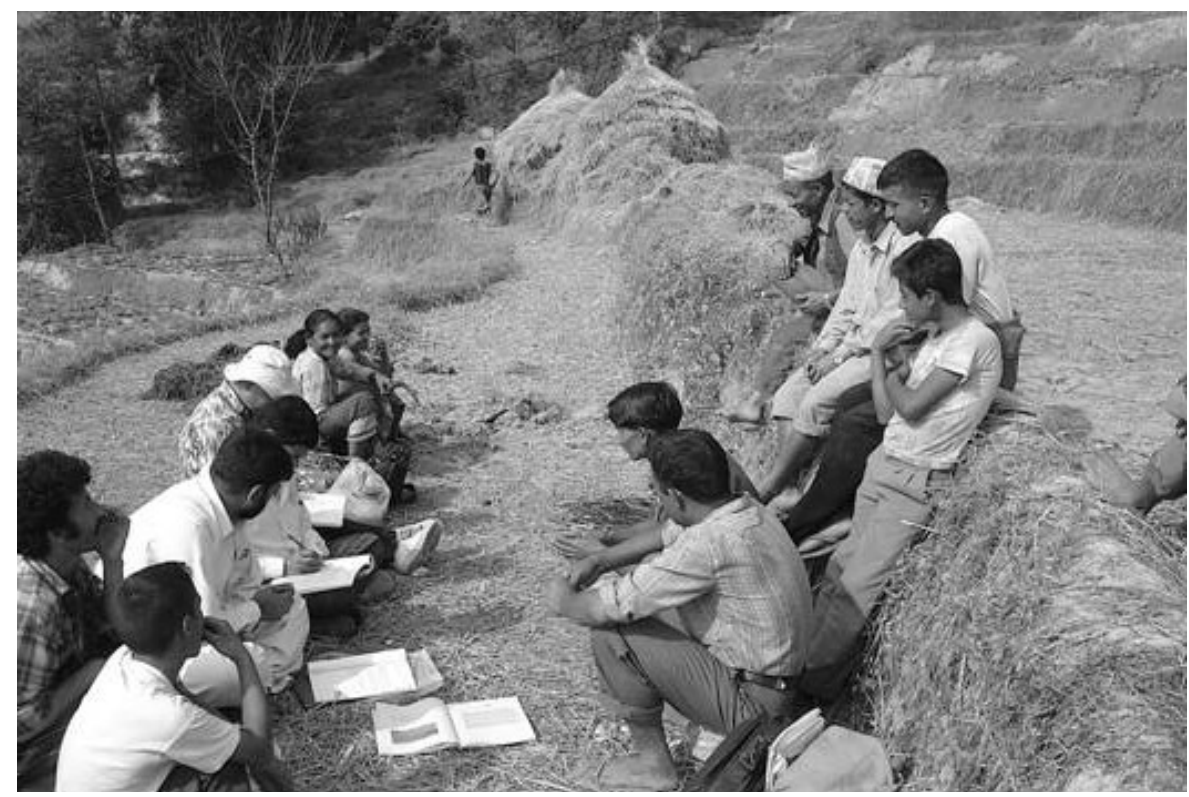

Fig. 9.9. SLM specialists using the WOCAT questionnaires to compile farmers' knowledge about traditional rice paddies in Nepal. Together, they evaluate the experiences made so far and discuss possible improvements (Photo: H.P. Liniger). 


\section{Investing in 'Bright' and 'Green' Spots}

Comparing the WOCAT approaches' analyses with bright spot's 'drivers' (Noble et al., Chapter 13, this volume), there are several clear overlaps. Not all have been mentioned in the foregoing but are nevertheless found in several WOCAT cases ('green spots'). Following the bright spot order of 'drivers', the connections - in summary form - are as given below:

1. Bright spots: quick and tangible benefits. WOCAT: low inputs and rapid benefits (especially yield increase) are common characteristics of success.

2. Bright spots: low risk of failure. WOCAT: related to (1) - additionally, risk reduction is very important, especially in poverty-stricken areas which depend on each year's harvest.

3. Bright spots: market opportunities. WOCAT: there is a close connection with the marketing of products/good prices and the conservation of resources.

4. Bright spots: aspiration for change. WOCAT: there is continuous change and adaptation to change.

5. Bright spots: innovation and appropriate technologies. WOCAT: there is abundant evidence of land users modifying technologies or developing innovations - to suit their local conditions.

6. Bright spots: leadership. WOCAT: leadership is intrinsic in the spontaneous spread of technologies and inherent in successful projects. Most important are local leadership and land users being at the forefront.

7. Bright spots: social capital. WOCAT: supporting land users and local organizations in using and enhancing their capacity to improve land management is often crucial.

8. Bright spots: participatory approach. WOCAT: involvement of all stakeholders and participation of land users are key for achieving impact.

9. Bright spots: property rights. WOCAT: land tenure is explicitly important, especially secure access to land and its resources.

10. Bright spots: supportive policies. WOCAT: supportive policies are crucial in creating an enabling environment for SLM and development generally.
WOCAT and the IWMI initiative both emphasize the importance of focusing on bright spots, both to document these well and to analyse their key elements, identifying the 'drivers' that create them, and to come up with conclusions and assessing their implications for policy. While the bright spots initiative focuses on water and is of limited duration, it has stimulated awareness. WOCAT's focus is both long term and broad. It incorporates the link between water, soil fertility and the importance of the natural and human environment. Both the bright spots and WOCAT initiatives are complementary efforts. This wealth of good land management practice information has yet to be fully tapped.

It is appropriate to conclude by restating the main, overall conclusions and policy suggestions (Box 9.10) from Where the Land is Greener. This we do, verbatim.

The cases presented in this book demonstrate the value of investing in rural areas despite recent global trends of neglecting agriculture and focusing on industry and the service sector.

Ecologically, SLM technologies - in all their diversity - effectively combat land degradation. But a majority of agricultural land is still not sufficiently protected, and SWC needs to spread further. The potential ecosystem benefits go far beyond reducing soil erosion and water loss; these include regulation of watershed hydrological function - assuring base flows, reducing floods and purifying water supplies - as well as carbon sequestration, and preservation of above and below-ground biodiversity.

Socially, SLM helps secure sustainable livelihoods by maintaining or increasing soil productivity, thus improving food security and reducing poverty, both at household and national levels. It can also support social learning and interaction, build community spirit, preserve cultural heritage, and counterbalance migration to cities.

Economically, SLM pays back investments made by land users, communities or governments. Agricultural production is safeguarded and enhanced for small-scale subsistence and largescale commercial farmers alike, as well as for livestock keepers. Furthermore, the considerable off-site benefits from SLM can often be an economic justification in themselves.

(WOCAT, 2007) 
Box 9.10. Points for policy makers: overall

Investment in rural areas and SLM is a local concern, a national interest and a global obligation. Thus it must be given priority:

- At the local level: to increase income, improve food security and sustain natural resources - thus helping to alleviate poverty in areas where the livelihoods of the majority depend on agricultural production.

- At the global and national level: to safeguard natural resources and ecosystem services and in many cases to preserve cultural heritage.

Investments in SLM must be carefully assessed and planned on the basis of properly documented experiences and evaluated impacts and benefits: concerted efforts are needed and sufficient resources must be mobilized to tap the wealth of knowledge and learn from SLM successes. These investments will give 'value for money' in economic, ecological and social terms.

\section{References}

Haggblade, S. (ed.) (2004) Building on successes in African agriculture. Focus 12, Brief 1 of 10. International Food Policy Research Institute, Washington, DC.

Hurni, H., Liniger, H.P. and Wiesmann, U. (2005) Research partnerships for mitigating syndromes in mountain areas. In: Huber, U.M., Reasoner, M.A. and Bugmann, H. (eds) Global Change and Mountain Regions: a State of Knowledge Overview. Kluwer Academic Publishers, Dordrecht, the Netherlands.

Liniger, H.P. and Schwilch, G. (2002) Better decision making based on local knowledge - WOCAT method for stainable soil and water management. Mountain Research and Development Journal 22 (1), 14-18.

Liniger, H.P., Cahill, D., Thomas, D.B., van Lynden, G.W.J. and Schwilch, G. (2002) Categorization of SWC technologies and approaches - a global need? Proceedings of International Soil Conservation Organization (ISCO) Conference, 26-31 May 2002, Beijing, Vol. III, pp. 6-12.

Liniger, H.P., Douglas, M. and Schwilch, G. (2004) Towards sustainable land management - 'Common sense' and some of the other key missing elements (the WOCAT experience). Proceedings of International Soil Conservation Organization (ISCO) Conference, 4-9 July 2004, Brisbane, Australia.

McNeely, J.A. and Scherr, S.J. (2003) Ecoagriculture. Island Press, Washington, DC.

Page, K. and Ramamonjisoa, N. (2002) NRM tracker review: examples of local-level initiatives from subSaharan Africa. International Resources Group, Washington, DC.

Reij, C and Steeds, D. (2003) Success stories in Africa's drylands: supporting advocates and answering critics. Global Mechanism of the Convention to Combat Desertification, Rome.

Rochette, R.M. (1988) Le Sahel en lutte contre la désertification: leçons d'expériences, document élaboré par le CILSS, GTZ, PAC, Deutsche Gesellschaft für Technische Zusammenarbert (GTZ), Eschborn, Germany.

UNEP (United Nations Environment Program) (2002) Success stories in the struggle against desertification. United Nations Environment Programme, UNEP, Nairobi, Kenya.

WOCAT (2004) CD-ROM V3: World Overview of Conservation Approaches and Technologies: Introduction Network - Questionnaires - Databases - Tools - Reports. FAO Land and Water Digital Media Series 9 (rev.), Food and Agriculture Organisation, FAO, Rome.

WOCAT (World Overview of Conservation Approaches and Technologies) (2007) Where the Land is Greener. Case studies and analysis of soil and water conservation initiatives worldwide. Liniger, $\mathrm{H}$. and Critchley, W. (eds) CTA, Wageningen, the Netherlands. 